\title{
Structural characteristics of discourse communication
}

\author{
Yana Vladimirovna Zubkova ${ }^{1, *}$, and Inna Konstantinovna Kirillova ${ }^{1}$ \\ ${ }^{1}$ Moscow State University of Civil Engineering. 26, Yaroslavskoe shosse, 129337, Moscow, Russia,
}

\begin{abstract}
At the present paper the aspects of linguistic consciousness and communicative behaviour are discussed. Some likeness between the concepts reflected in linguistic consciousness and the scripts reflected in communicative behaviour are described. Valuable components are expressed in the text through inner composition meaning, determined by the stereotypes as well as through the image of the situation (the setup) and the succession of communicative steps - the scenes (the scenario). According to the axiological linguistics communicative behaviour can be represented as a multifayer formation with the following components: meaning, set up, scenario, script. An example of communicative behaviour of lecture participants in the academic discourse is given. The typical actions of participants in the communication are based on the situation and determined by their cultural values.
\end{abstract}

\section{Introduction}

The discourse based on axiological linguistics is considered as a multidimensional communication model: it has a certain style, mediated by culture and manifested in the selection of linguistic means, the meaning organization, the nationally marked behavior of communicant, and includes strategies and tactics of speech behavior of participants in social actions, as well.

The world of meanings is connected with interpretation. The meanings interpretation floats around the communication space defining the values of consciousness of the linguistic personality, the socium, the culture and the civilization as a whole $[1,6,7,8,9]$.

In modern linguistics, there are various theories of knowledge representations now. The scope of linguistics interests includes issues affecting the cultural and social characteristics of linguistic personality. The study and analysis of linguistic concepts demonstrate the achievements of linguists in language learning as mobile structure, influenced by culture, society and individuals.

Nowadays the linguists' interest is focused around the quanta of the current knowledge - the concepts, which include the notion about the subject or the event, its image (group or individual) and value components [2]. These typical actions of the participants of communicative situations are specified by their cultural values, are expressed in the normative forms of the utterance and exist in close connection with other forms of the utterance.

For example, the concept "punctuality", which we have been studying, according to this linguistic and cultural / axiological theory, is made up by the following:

1. The subject-image part of the concept - that is the generalized image of the strict correspondence between the necessary and the factual correlation of the created events in time.

2. The notional part of the concept - that is the implied norm of the correspondence mentioned above which is opposed to the violations of this norm and is specified by the intensifiers.

3. The value part of the concept - that is the evaluative attitude towards the following and the violation of the corresponding norm [11].

Linguistic and cultural concepts expressing the fragmented experience of the linguistic personality should be looked at within the framework of the communicative behaviour.

The researchers describe the typical actions of the participants of communication, equating the typical communicative situations and the speech genres, emphasizing genre norms, allowing for the typical forms of definite personality utterances [12].

These typical actions of the participants of communicative situations are specified by their cultural values, are expressed in the normative forms of the utterance and exist in close connection with other forms of the utterance.

\section{Materials and methods}

The study of the mental activity of language personality expressed through communicative behavior allows conducting research not only in verbal communication, but also in situation communication.

The methodology of the considered discourse studying has the following algorithm:

- to choose the topic of the discourse,

- to select texts related to the topic and created by participants of the discourse,

\footnotetext{
* Corresponding author: yanazubkova@yandex.ru
} 
- to carry out a structural analysis: to rate data of the selected "discursive line",

- to analyze texts (discourse situations) in detail according to their place in the system of all selected texts/ situations,

- to analyze the scenario of this communication (occurrence and deployability over time).

We consider the study of texts to be promising: a detailed study of meanings, as discursive categories, which will allow us to describe the linguistic corpus of various types of discourses.

We propose to study discourse from the perspective of the cultural characteristics of speech, since we believe that discourse is communication within the framework of a conceptual field that has temporal, spatial, cultural, institutional, and textual frameworks; value communication.

The structure of the discourse communication (central topics and main approaches) is important for our research.

\section{Results}

The discourse organisation is preserved throughout different definitions, which stands for its wellformedness, predeterminacy, coordinated continuity. The discourse is always connected with some interests. The language as a system makes the discourse follow some definite rules (this is the cultural difference of a discourse).

We agree with the idea that a discourse presented as a text "has not a pure linguistic but linguistic-cognitive nature, i.e. it belongs to the sphere of mental in the language [5]. This is the logical reason for describing communicative behaviour of the personality and the analysis of discourse practices and some speech acts while studying linguistic consciousness.

We believe that communicative behaviour can be described only taking into consideration such factors as artifacts (spacetime), representations, expectations, stereotypes, norms and values (determined culturally, socially and personally).

The differences in the description of linguistic consciousness and communicative behaviour are initially based on the essence of these absolutely different phenomena [3]. Static character is in the heart of consciousness, while behaviour is dynamic in its sense and is possible to be presented both in time and space. In spite of this circumstance the aspects, found out while studying these phenomena, are not controversial to each other but rather have identical patterns.

The essence of linguistic consciousness and communicative behaviour may be presented in the following way:

- Linguistic consciousness: meaning presuppositions - implications - concept.

- Communicative behaviour (discourse): meaning - set up - scenario - script.

The word meaning is formed in the linguistic consciousness and is the product of a person's mental activity; it is connected with the reduction of the information which consciousness produces; it has generic and generalised character and is used as the material for concepts formation [10]. The conceptualisation of the reality is based on the cognitive learning of reality.

While behaviour reflects the knowledge about the reality, the information as the result of culture learning. Acquiring the knowledge a person transforms the meaning into some background components: the truth based component - presuppositions (the conceptual component of meaning) and logical component implications (the evaluative component of meaning), which is expressed in the pattern "if...then...".

Besides, the consciousness is defined by the meanings - the units of consciousness ultimate expression, which are formed in communicative behaviour (these are concepts in linguistic consciousness). Here we speak preeminently about valuable components expressed in the text through inner composition meaning, determined by the stereotypes as well as through the image of the situation (the setup) and the succession of communicative steps - the scenes (the scenario).

It's logical, to our view, to observe some likeness between the concepts reflected in linguistic consciousness and the scripts reflected in communicative behaviour. Concepts and scripts belong to the same kind of phenomena: a concept functions statically in the language [4] and a script functions dynamically in the discourse. We stick to the idea of the importance of value constituent in consciousness and communicative behaviour.

By scenario we understand some plan, created in advance, while a script is the way valuable events, including social, cultural, individual norms of a person's (a linguistic person's) behaviour, are understood. These are the models of representations of valuable events.

Communicative behaviour represents a multilayer formation with the following components to be distinguished:

1) communicative steps, the succession of which is the script of the definite behaviour in lines of this or that discourse genre;

2) participants of communication intentions, the whole of which is the institutional content of the communication ;

3) communicative values, which determine the spread of the discourse and express themselves in a concrete way as linguistic cultural scripts, i.e. culturally determined algorithms of communication in this or that communicative sphere and situation.

To refer communication to a certain type of discourse it is necessary to identify the set of semantic unities (concepts) of the given type of communication. Thus we consider the concepts of "a University", "a lecturer", "a lecture", "higher education", etc. to be such a set of semantic unities for the academic discourse. Taking the genre of a lecture, as an example, the discourse communication structure is analysed. A lecture is considered to be a genre of academic discourse as it is a form of academic studies in the system of high education. 
A lecture (from lat. lectio - reading) is a systematic successive coverage of the information to be studied, some question, theme, abstract, subject, scientific methods. The lectures may be academic and public. An academic lecture is one of the forms of the process of studies and is one of the main methods of teaching in a high educational institution.

The participants of a lecture are students and a lecturer. The place where an academic lecture may be held is a room in a high educational institution. Knowing the time and space and the participants of communication we can determine the discourse genre (lecture) and the type of the discourse (academic discourse).

Having a stereotype of how a lecture should be held the participants of communication act according to the definite scenario: the Russian culture presupposes the scenario according to which the lecturer reads out the lecture, delivers the knowledge, and the student gets the idea of one of the parts of the academic subject.

We suggest taking this stereotype as a cultural one. And we believe that stereotypes will have different content depending on their national origin. For example, in Russian academic tradition the students expect to get some evaluation of scientific theories and methods from the lecturer.

The situation in which the participants of the lecture find themselves presupposes some institutional communication, i.e. the communication from the position of the communicant's status. This category of status predominates while choosing the stereotypical norms of the linguistic person behaviour.

A lecturer is a highly qualified specialist of some high educational institution who delivers some subject, teaches the students, gives them information from some sphere of knowledge.

A student, being a member of some high educational institution, is positioned on the other stage of institutional, discourse if compared to a lecturer.

The Russian cultural code contains the stereotype according to which a lecturer is very well educated person of wide reading and a student is a young person who obtains knowledge and spends his or her time during a lecture having fun and going about his or her own business.

The participants of communication stick to the stereotypical norms of behaviour or violate them. It depends on the values of the participants of communication, connected with their social roles, and their personal preferences, determined by the situation and their background.

The norms of behaviour and the violation of these norms is connected with the participant's system of values. If a lecturer performs his or her social role of a teacher, they deliver the information during a lecture pointing to advantages and disadvantages of this or that position and refraining from giving their personal evaluation of the subject.

If a lecturer performs a role of a mentor, they possibly will "teach" a student to believe that something is true and something is not, will evaluate a theory, will demand to have some definite attitude towards the events or the facts and will instruct a student on how to study and what to study. It means that a lecturer may use the authoritarian behaviour scenario.

To identify strategies for academic discourse the communicative situation can be described in terms of the discourse genre. First of all, in the academic discourse, we single out a learning strategy that is implemented in the following

Teachers' speech and tactics are:

- informative (presentation of theoretical material);

- explanatory (criticism of theories and opinions);

- evaluating (assessment of work, student responses);

- motivation (student's motivation for study);

- institutional (presentation style of educational material);

- presentations (a way of presenting material using

multimedia tools, diagrams, posters).

The main student's strategy should be considered a strategy of cognition. At the lecture, the student's communicative behavior is realized in tactics:

- expectations (inert behavior is due precisely to the desire to receive answers to questions for the exam / test and the seminar);

- a question (students can ask questions at a lecture);

- clarification (students write the teacher's words word for word, sometimes without thinking about the context, so this tactic is often implemented in a lecture);

- self-presentations (usually a lecture is given by teachers, taking the exam, so for some students it's important to attract examiner's attention, make him notice himself in a large audience).

The organization of the discourse indicates its unconditional design, presetness, coordinated sequence.

A script is a culturally determined communication algorithm in a particular communication field and situation that describes a communication situation, including:

1) subject or title ;

2) a list of items that are included in the sequence of actions;

3) prerequisites for action;

4) roles;

5) consequences;

6) the procedure for the implementation of actions.

\section{Discussion}

To sum up, the values of academic communication are expressed through the main demands towards the way the information should be given during a lecture: it should be illustrative, scientific and academically continual. The values should be provided by means of institutionality and determined by the attitude to culture.

This brief description of communicative behaviour of the participants of the lecture allows us to define the values determining a lecturer's and a student's behaviour. A student and a lecturer perform their social roles according to their cultural code and personal system of values.

We suggest understanding a script as a pattern of a communicative event and describing the behavioural acts 
of the discourse participants according to cultural norms and values.

We consider finding out the concepts of some definite discourse to be a very important part in the investigation of scripts.

The script of academic discourse is a values conditioned sequence of communicative steps in the academic communication between the lecturer and the students. This sequence includes dominants of academic communication within the scope of high school.

A lecture should be considered a script of an academic discourse because during the communication at the lecture one can describe and explain communicative behaviour of the participants in development, find out cultural values, communicative values within the scope of high school in general as well as linguistic personality values in particular.

Thus the situation of an academic discourse is a genre of a lecture; the knowledge is the understanding of the essence of the lecture; the setup is following or nonfollowing the norms of behaviour; the script is the evaluative attitude towards following or non-following the norms of behaviour.

\section{Conclusion}

A discourse in the broad sense is a socially determined organization of the speech system, as well as certain principles in accordance with which reality is classified and represented in certain periods of time.

The organizational content of the dicourse is preserved in various definitions, which indicates its unconditional design, preset, consistent sequence. The discourse is always connected with some interests:

- the language, as a system, imposes its own rules on the discourse (this expresses the cultural specificity of the discourse);

- discourse (like communication, within a certain social group, in connection with a certain communication situation) is determined by the conditions of communication and is based on certain stereotypes, rules, determined by space and time.

In addition, it is possible to study the discourse as a result of a process. The situation in the context of Who? Where? When? is predetermined (actual) and can be described from the perspective of the situation. The unfolding scenario of behavior within the framework of the norms of communication adopted in this situation and used by communicants depending on group and personal values, is a unfolding process.

To summarize the ideas of this article it should be noted, that:

1. The discourse in its wide meaning is socially conditioned organisation of speech and some definite principles, according to which one can classify and represent the reality in some periods of time.

The discourse can be analysed with the tools of axiological linguistics.

2. Discourse can be described using a pattern, based on such characteristics as: meaning - set up - scenario script.
3. To describe a script we need to put the concept in some cultural, situational, contextual space of the language, that is, discourse.

The prospect of the discourse studying is to conduct a general analysis of the possible communication situations, of the participants, of a certain type of discourse and to identify the features of the discourse type's influence on society and culture.

\section{References}

1. L. Alba-Juez, Russian Journal of Linguistic, Discourse Analysis and Pragmatics: Their Scope and Relation, , 20 (4), 43-55 (2016).

2. V.I. Karasik, Yazykovaya spiral': values, signs, motives, Volgograd: Paradigm (2015).

3. V.I. Karasik, Russian Journal of Linguistics, Algoritmy postroeniya komicheskih textov, 22 (2018)

4. N.A. Krasavsky, Voprosy kognitivnoy lingvistiki, Emotsional'naya kontseptosfera nemetskogo yazyka: opyt etimologicheskoy lingvistiki, 1. (2005)

5. V.V. Krasnych, Voprosy psikholingvistiki, Yedinitsy yazyka vs. yedinitsy diskursa $i$ lingvokul'tury $(k$ voprosu o statuse pretsedentnykh fenomenov $i$ stereotipov), Izdatel'stvo: Moskovskaya mezhdunarodnaya akademiya (Moskva), 7, 53-58 (2008)

6. L.V. Kulikova, Journal of Siberian Federal University. Humanities and Social Sciences, Technologisation of discourse practices: globality versus cultural specificity, 5 (12), 1753-1761 (2012)

7. O.V. Lutovinova, Issues of Cognitive Linguistics, Yazykovaya kartina virtual'nogo mira. Problema kontseptualizatsii, 3, 21-29, (2009)

8. R. Vodak, Yazyk. Diskurs, Volgograd: Peremena. (1997). ISBN 5-88234-249-X

9. M.R. Zheltukhina, A.V. Zinkovskaya, V.V., Katermina, N.B. Shershneva, International Journal of Environmental and Science Education, Dialogue as a Constituent Resource for Dramatic Discourse: Language, Person and Culture, 11(15), 7408-7420 (2016). eISSN 1306-3065.

10. Y.V. Zubkova, Ivzestia of the Volgograd State Pedagogical University. Philology, Lingvokul'turnyye skripty $v$ akademicheskom diskurse. 5 (29), 34-38, (2008).

11. Y.V. Zubkova, Voprosy psikholingvistiki, Skripty punktual'nogo povedeniya $v$ nemetskoy $i$ russkoy lingvokul'turakh (na materiale psikholingvisticheskogo experimenta), 7, 90-93 (2008).

12. I.A. Zyubina, G.G. Matveeva, M.R. Zheltukhina, G.G. Slyshkin, A.V. Shevchenko, XLinguae, Forensic prosecutor's speech as a speech genre, 10 (3), 312-323 (2017) 
